\title{
Gender differences in the perception of quality of life of patients with colorectal cancer
}

\author{
Isadora Trinquinato' \\ Rodrigo Marques da Silva ${ }^{2}$ \\ Sonia Betzabeth Ticona Benavente ${ }^{3}$ \\ Camila Cristine Antonietti ${ }^{4}$ \\ Ana Lúcia Siqueira Costa Calache ${ }^{5}$
}

\section{Gender differences in the perception of quality of life of patients with colorectal cancer}

Objective. to identify the gender differences in assessing quality of life of patients undergoing chemotherapy treatment for colorectal cancer. Methods. this is a crosssectional investigation conducted with 144 patients (72 men and 72 women) undergoing chemotherapy treatment in a southeastern Brazilian hospital. Data were gathered trough a sociodemographic and clinical information form and the Health-related Quality of Life instrument from the European Organization for Research and Treatment of Cancer. Results. cognitive function leads to lower general quality of life, with higher effect in men when compared to women. Body image $(p=0.023)$, abdominal pain $(p=0.020)$ and dry mouth $(p=0.001)$ produced lower quality of life in women. On other hand, men showed lower quality of life related to the following symptoms: fecal incontinency $(p<0.001)$, sexual impotency $(p=0.027)$ and sexual arousal $(p<0.001)$. Conclusion. the illness symptoms and chemotherapy treatment effects that negatively impact on quality of life differ between men and women. Thus, healthcare needs to be focused on these specific factors that affect the quality of life according to the patient's gender.

Descriptors: body image; quality of Life; cross-sectional studies; colorectal neoplasms.

\section{Diferencias de género en la percepción de calidad de vida de pacientes con cáncer colorrectal}

Objetivo. Identificar las diferencias de género en la percepción de la calidad de vida de pacientes con cáncer colorrectal. Métodos. Estudio transversal, realizado con 144 pacientes (72 hombres y 72 mujeres) en tratamiento quimioterapéutico en un hospital del

\footnotetext{
1 Nurse. Undergraduate course. University Hospital of Jundiaí. Jundiaí, SP, Brazil. email: isadora.trinquinato@usp.br 2 Nurse, Master, Ph.D. student. USP, São Paulo, SP, Brazil. email: marquessm@hotmail.com

3 Nurse, Ph.D. student. USP, São Paulo, SP, Brazil. email: sonibenavente@usp.br

4 Nurse, Ph.D. student. USP, São Paulo, SP, Brazil. email: camis.antonietti@gmail.com

5 Nurse, Ph.D. Associate Professor, USP, São Paulo, SP, Brazil. email: anascosta@usp.br Conflict of interests: None.

Recieved: June 8th 2017.

Accepted: August 18th 2017.

How to cite this article: Trinquinato I, Silva RM, Benavente SBT, Antonietti CC, Calache ANSC. Gender differences in the perception of quality of life of patients with colorectal cancer. Invest. Educ. Enferm. 2017; 35(3): $320-329$

DOI: 10.17533/udea.iee.v35n3a08
} 
sudeste brasilero. Los datos se recogieron a partir de un cuestionario sociodemográfico y clínico y del instrumento de Cualidad de Vida Relacionada a Salud del European Organization for Reseach and Treatment of Cancer. Resultados. La función cognitiva lleva a menor calidad de vida general, con mayor impacto en los hombres comparados con las mujeres. La imagen corporal $(p=0.023)$, el dolor abdominal $(p=0.020)$ y la boca seca $(p=0.001)$ representan menor calidad de vida en las mujeres, mientras que en los hombres son los síntomas: incontinencia fecal $(p<0.001)$, impotencia sexual $(p=0.027)$ y el interés sexual $(p<0.001)$. Conclusión. Los síntomas de la patología y los efectos del tratamiento quimioterapéutico reducen la calidad de vida en forma diferente en hombres y mujeres. Así, los cuidados en salud deben enfocarse en los factores específicos que impactan en la calidad de vida según el sexo.

Descriptores: imagen corporal; calidad de Vida; estudios transversales; neoplasias colorrectales.

\section{Diferenças de gênero na percepção de qualidade de vida em pacientes com câncer colorretal}

\section{Introduction}

Colorectal cancer has become a public health problem in Brazil and the world. In Brazil, 34,280 new cases are estimated for 2016, with an incidence of $7.8 \%$ in men and $8.6 \%$ in women (respectively third and second place in the Brazilian population without considering non-melanoma skin tumors). (1) The southeastern Brazilian region has the highest incidence of this type of tumor and ranks second among men and women with 19,950 new cases per year (20.6\%). ${ }^{(1)}$ The most common type of colorectal cancer is sporadic, characterized by affecting individuals over 50 years of age, with no family history or hereditary intestinal diseases. This type originates from normal cells of the body that, when exposed to a series of aggressions, accumulate mutations in some genes, resulting in clonal proliferation. However, there are other types such as Familial Adenomatous Polyposis Syndrome and Lynch Syndrome or Hereditary Non-Polyposis Colorectal Cancer Syndrome. (2) Colorectal cancer can develop from exposure to a variety of factors, including: in-
Objetivo. Identificar as diferenças de gênero na avaliação de qualidade de vida dos pacientes em tratamento quimioterápico para câncer colorretal. Metodologia. Estudo transversal, realizado com 144 pacientes (72 homens e 72 mulheres) em tratamento quimioterápico. Para coletar os dados, aplicaram-se um questionário sóciodemográfico e clínico e o instrumento de Qualidade de Vida Relacionada à Saúde da European Organization for Reseach and Treatment of Cancer. Resultados. A função cognitiva leva a menor qualidade de vida geral, com maior impacto nos homens quando comparado às mulheres. $\mathrm{A}$ imagem corporal $(p=0.023)$, a dor abdominal $(p=0.020)$ e a boca seca $(p=0.001)$ representam menor qualidade de vida às mulheres. Já os homens apresentam menor qualidade de vida devido aos sintomas: incontinência fecal $(p<0.001)$, impotência sexual $(p=0.027)$ e interesse sexual $(p<0.001)$. Conclusão. Os sintomas da doença e os efeitos do tratamento quimioterápico que reduzem a qualidade de vida diferem entre homens e mulheres. Assim, os cuidados em saúde devem se voltar aos fatores específicos que impactam na qualidade de vida segundo o gênero.

Descritores: imagen corporal; qualidade de vida; estudos transversaies; neoplasias colorretais.

adequate eating habits - excessive consumption of red meat, processed meat, alcohol, refined sugars, a high-fat and low-fiber diet - smoking, sedentary lifestyle, and daily stress. ${ }^{(3)}$ Treatment for colorectal cancer depends on the size, location, extent of tumor, and health conditions of the individual. The main types of treatment include surgery, chemotherapy and radiotherapy. The chemotherapeutic treatment may be neo-adjuvant, adjuvant or palliative for patients with stage II, III and IV colorectal cancer. ${ }^{(2)}$ Despite the benefits of this treatment, there are still some side effects due to the toxicity of chemotherapeutic drugs, a phenomenon that causes physical discomfort and limits daily activities. Added to this, the disease's own symptoms and the whirlwind of psychoemotional changes, which may include sadness, depression, anxiety, social isolation and existential and spiritual crisis, ${ }^{(4)}$ negatively impact the quality of life.

The World Health Organization defines quality of life as a multidimensional concept that includes individuals' perceptions of their position in life in the context of the cultural and value sys- 
tems in which they live and in relation to their goals, standards, expectations and concerns. ${ }^{(5)}$ In turn, the European Organization for Research and Treatment of Cancer brings the term of quality of life by relating it to health in order to understand the general effect of cancer on the patient as a "whole human being." Thus, quality of life is defined as a multidimensional concept encompassing key dimensions such as: symptoms related to disease and treatment, physical, psychological and social functioning. ${ }^{(6)}$ A longitudinal cohort study of 453 colon cancer patients at stage II identified lower levels of quality of life in those receiving chemotherapy compared to those who did not receive chemotherapy. ${ }^{(7)}$ In another study conducted with 16 patients aged between 43 and 75 years and with colorectal cancer and under chemotherapy, the patients assessed their quality of life as unsatisfactory and the meanings attributed to it were: loss of normal life, personal and social suffering and the need to react to the side effects of chemotherapy, which is a preliminary step to cure. ${ }^{(8)}$

Thus, since patients under chemotherapy treatment may have a greater negative impact on their quality of life, it becomes relevant to investigate gender differences, as men and women present individual, social, physical and psychological particularities, which reflects in the coping of the disease and impacts of treatment in various ways. Various authors ${ }^{(9,10)}$ have discussed gender differences and their individual cultural aspects; however, in the literature there are few studies evaluating gender differences in relation to quality of life in colorectal cancer. Studies analyzing colorectal neoplasia have shown a strong association between the psychoemotional manifestations of stress and the therapeutic actions of cancer. However, few of the gender-related peculiarities are considered a relevant factor in the evaluation of the quality of life of patients. Therefore, the purpose of this study is to identify gender differences in the quality of life of patients undergoing chemotherapy for colorectal cancer.

\section{Methods}

This is a cross-sectional and analytical study conducted in a hospital in the southeast of Brazil aimed at the care of cancer patients. The study sample was non-probabilistic for convenience. It consisted of 144 patients on outpatient chemotherapy for colorectal cancer, aged 21 years or older, with preserved communication and comprehension ability, with or without previous surgical treatment, being in the third week of treatment with fluorouracil (5FU) + leucovorin or at least having received the first cycle of oxaliplatin + leucovorin $+5 F U$.

Data were collected from January to October 2012 through an interview conducted by the leading investigator at the time patients received the chemotherapy treatment. The instruments used in this phase were: the sociodemographic and clinical questionnaire, the European Organization for Reseach and Treatment of Cancer - (EORTC-QLQQ30), which evaluates the general quality of life, and the European Organization for Reseach and Treatment of Cancer - Colorectal Cancer (EORTCQLQ-CR29), specifically targeted to patients with colorectal cancer. The clinical and sociodemographic form involved the variables age, gender, marital status, schooling, employment status, sick leave, social class (from A to $E$, being "A" the highest class and " $E$ " the lowest), religious practice and monthly income.

The Health-Related Quality of Life instrument of the European Organization for Reseach and Treatment of Cancer (EORTC-QLQ-Q30) was built in $1993^{(11)}$ and validated for the Brazilian reality in 2010.(12) It is a general quality of life questionnaire (EORTC QLQ-C30) that includes 30 questions related to five functional scales (physical, functional, emotional, social and cognitive), a scale on the overall health status, three scales of symptoms (fatigue, pain and nausea/vomiting) and six items of additional symptoms (dyspnoea, insomnia, loss of appetite, constipation, diarrhea and financial distress. ${ }^{(11,12)}$ The answer options are four-point Likert type (1-no, 2-a little, 3-fair and 4-a lot), except for the measurement of general health status and quality of life that has a sevenpoint Likert scale (1- poor and 7-great). Higher scores for the items on the functional scales represent a better quality of life. On the items of the symptom scale, higher scores represent worsening of quality of life. ${ }^{(13)}$ 
The Health-related Quality of Life tool from the European Organization for Research and Treatment of Cancer (EORTC-QLQ-CR29) assesses quality of life in a specific way for patients with colon and rectal cancer. This instrument has 29 items divided into two functional scales (body image and sexual function) and seven items of signs/symptoms (urinary problem, chemotherapeutic drug effect, gastrointestinal tract alterations, sexual dysfunction, sphincter alteration, stoma-related problems, pain). Some items are answered by all patients and the others by subgroups (men, women and those with or without stoma). Values ranging from one to four ( $1=$ nothing, 2 = a little, $3=$ a lot, $4=$ too much) are assigned to the items. All scales and items are transformed into scores ranging from 0 to $100^{(14)}$. High scores on the functional scale represent a better quality of life. On the symptom scale items, higher scores represent worsening of quality of life. ${ }^{(14)}$

The data were entered into a spreadsheet in the Microsoft Office Excel 2007 program. Data analysis was performed by the Statistical Package for Social Sciences (SPSS) software program, version 19.0. The qualitative variables were described in absolute (n) and relative frequency (\%) and quantitative variables were described in measures of central tendency (mean and median) and dispersion (standard deviation, minimum and maximum). To evaluate the association between the nominal measures of sociodemographic and clinical variables of the disease and gender, Pearson's Chi-square test or Fisher's exact test was used. The association of quantitative sociodemographic variables and quality of life with the gender was performed using Student's t-test. The level of significance was set at $5 \%$.

The informed consent form was given to the subjects who agreed to participate in the study after receiving explanation on the objectives of the stu$d y$, and they signed it in two copies; one was given to the researcher and the other remained with the research subject. This study is part of a larger study that evaluated the perception of stress, social support, sense of coherence, resilience and the quality of life of patients with colorectal cancer under chemotherapy treatment and was approved by the Research Ethics Committee of the Nursing School of the University of São PauIo (CEP - EEUSP - Protocol No. 1005/2011 and CAAE No. 0009.0.196.000-11).

\section{Results}

The analysis of the 144 patients is presented through gender comparison according to sociodemographic and clinical variables, followed by the comparative analysis of general quality of life and scales of symptoms and body image between men and woman with diagnosis of colorectal cancer and undergoing chemotherapy treatment. Table 1 shows the gender comparison according to the sociodemographic variables in this population. There was prevalence of married patients, with elementary education, social class $\mathrm{C}$, and religious practice in both groups. However, it is observed that men remained active in the labor market, but with sick leave. On the other hand, women were mostly retired, which explains the predominance of absence of sick leave in this group.

In addition, the average monthly income of men ( $R \$ 2060.5, S D=707.6$, exchange rate in October 2012: 1.00 USD = R $\$ 2.08$ ) is higher than that of women ( $R \$ 1432.8, S D=1266.7)$, but the average age is higher among women (58 years; SD $=10.3$ ) when compared to men ( 56 years; SD = 12.4), with a general average age of 56.92 (SD = 11.4) years. Table 2 shows the gender comparison in relation to the clinical variables of the patients.

Table 2 shows there was no statistically significant difference between men and women for the analyzed variables, with predominance in both groups of patients with colon tumor, in stage III, undergoing adjuvant treatment and surgery, having a family history of cancer and absence of stomas.

Table 3 shows the comparison between men and women in relation to general quality of life (EORTCQLQ-Q30). In this study, it is observed that cognitive function leads to lower general quality of life, with greater impact in men when compared to women. The other variables did not present a significant difference between males and females. 
Table 1. Gender comparison according to sociodemographic variables of patients with colorectal cancer

\begin{tabular}{|c|c|c|c|c|c|}
\hline \multirow{3}{*}{ Variable } & \multicolumn{4}{|c|}{ Gender } & \multirow{3}{*}{$p$ value } \\
\hline & \multicolumn{2}{|c|}{ Male $(n=72)$} & \multicolumn{2}{|c|}{ Female $(n=72)$} & \\
\hline & $n$ & $\%$ & $n$ & $\%$ & \\
\hline \multicolumn{6}{|l|}{ Marital status } \\
\hline Single/Divorced/Widowed & 1 & 1.4 & 11 & 15.3 & 0.004 \\
\hline Married/Living with family or partner & 71 & 98.6 & 61 & 84.7 & \\
\hline \multicolumn{6}{|l|}{ Schooling } \\
\hline Elementary school & 47 & 65.3 & 51 & 70.8 & 0.729 \\
\hline High school & 13 & 18.1 & 12 & 16.7 & \\
\hline Higher education & 12 & 16.7 & 9 & 12.5 & \\
\hline \multicolumn{6}{|l|}{ Employment Situation } \\
\hline Retired & 18 & 25.0 & 28 & 39.4 & 0.008 \\
\hline Unemployed & 8 & 11.1 & 18 & 22.5 & \\
\hline Active & 46 & 63.9 & 27 & 38 & \\
\hline \multicolumn{6}{|l|}{ Sick Leave } \\
\hline Yes & 41 & 69.5 & 26 & 43.3 & 0.004 \\
\hline No & 18 & 30.5 & 34 & 56.7 & \\
\hline \multicolumn{6}{|l|}{ Social class } \\
\hline A & 1 & 1.4 & 0 & 0 & $<0.001$ \\
\hline B & 29 & 40.3 & 10 & 13.9 & \\
\hline C & 41 & 56.9 & 55 & 76.4 & \\
\hline D & 1 & 1.4 & 6 & 8.3 & \\
\hline $\mathrm{E}$ & 0 & 0 & 1 & 1.4 & \\
\hline \multicolumn{6}{|l|}{ Religious Practice } \\
\hline Yes & 51 & 72.9 & 62 & 87.3 & 0.031 \\
\hline No & 19 & 27.1 & 9 & 12.7 & \\
\hline
\end{tabular}

Table 2. Gender comparison in relation to the clinical variables of the disease

\begin{tabular}{|c|c|c|c|c|c|}
\hline \multirow{3}{*}{ Variable } & \multicolumn{4}{|c|}{ Gender } & \multirow{3}{*}{$p$ value } \\
\hline & \multicolumn{2}{|c|}{ Male $(n=72)$} & \multicolumn{2}{|c|}{ Female $(n=72)$} & \\
\hline & $n$ & $\%$ & $n$ & $\%$ & \\
\hline \multicolumn{6}{|l|}{ Medical diagnostic } \\
\hline Colon Neoplasia & 60 & 83.3 & 60 & 83.3 & $1.00^{*}$ \\
\hline Junction Neoplasia Retosigmoid & 1 & 1.4 & 2 & 2.8 & \\
\hline Rectal Neoplasia & 11 & 15.3 & 10 & 13.9 & \\
\hline \multicolumn{6}{|l|}{ Tumor's Stage } \\
\hline I & 1 & 1.4 & 2 & 2.9 & $1.00^{*}$ \\
\hline II & 13 & 18.1 & 14 & 20.3 & \\
\hline III & 37 & 55.2 & 36 & 52.2 & \\
\hline IV & 16 & 23.9 & 17 & 24.6 & \\
\hline
\end{tabular}


Table 2. Gender comparison in relation to the clinical variables of the disease. (Cont.)

\begin{tabular}{lccccc}
\hline Type of Treatment & 44 & 63.8 & 47 & 65.3 & $0.615^{*}$ \\
Adjuvant & 3 & 4.3 & 1 & 1.4 & \\
Neo-adjuvant & 21 & 30.4 & 24 & 33.3 & \\
$\quad$ Palliative & - & - & 1 & 1.4 & \\
$\quad$ Induction & & & & & \\
Surgery & 68 & 95.8 & 69 & 95.8 & $1.000^{\dagger}$ \\
$\quad$ Yes & 3 & 4.2 & 3 & 4.2 & \\
$\quad$ No & & & & & \\
Family History of Cancer & 43 & 59.7 & 44 & 61.1 & $0.865^{\dagger}$ \\
$\quad$ Yes & 29 & 40.3 & 28 & 38.9 & \\
$\quad$ No & & & & & \\
Metastasis & 29 & 40.3 & 37 & 51.4 & $0.181^{\dagger}$ \\
Yes & 43 & 59.7 & 35 & 48.6 & \\
$\quad$ No & & & & & \\
Stoma & 26 & 36.6 & 18 & 25 & $0.132^{\dagger}$ \\
Yes & 45 & 63.4 & 54 & 75 & \\
No & & & & & \\
\hline
\end{tabular}

$\left(^{*}\right)$ Fisher's test; $\left(^{+}\right)$Chi-Square Test

Table 3. Comparison of men and women in relation to general quality of life (EORTC-QLQ-Q30)

\begin{tabular}{|c|c|c|c|c|c|}
\hline \multirow{2}{*}{ EORTC QLQ-C30 } & \multicolumn{2}{|c|}{$\begin{array}{c}\text { Male } \\
(n=72)\end{array}$} & \multicolumn{2}{|c|}{$\begin{array}{c}\text { Female } \\
(n=72)\end{array}$} & \multirow{2}{*}{$p$ value } \\
\hline & Mean & $\begin{array}{l}\text { Standard } \\
\text { deviation }\end{array}$ & Mean & $\begin{array}{l}\text { Standard } \\
\text { deviation }\end{array}$ & \\
\hline \multicolumn{6}{|l|}{ Functional scale } \\
\hline Physical Function & 82.78 & 18.70 & 76.53 & 23.68 & 0.082 \\
\hline Role Performance & 83.80 & 22.50 & 78.17 & 22.54 & 0.191 \\
\hline Cognitive Function & 88.89 & 16.80 & 78.64 & 22.39 & 0.002 \\
\hline Emotional Function & 78.01 & 21.95 & 70.19 & 26.78 & 0.058 \\
\hline Social Function & 81.94 & 27.79 & 73.94 & 29.64 & 0.098 \\
\hline \multicolumn{6}{|l|}{ Scale of symptoms } \\
\hline Fatigue & 21.60 & 25.35 & 22.85 & 27.53 & 0.779 \\
\hline Pain & 9.95 & 18.27 & 11.97 & 23.60 & 0.568 \\
\hline Nausea/Vomiting & 12.04 & 18.60 & 17.37 & 25.57 & 0.156 \\
\hline Dyspnea & 7.87 & 20.55 & 7.98 & 19.89 & 0.974 \\
\hline Insomnia & 20.37 & 30.92 & 26.29 & 35.14 & 0.287 \\
\hline Lack of appetite/Anorexia & 14.35 & 28.97 & 21.60 & 34.31 & 0.175 \\
\hline Constipation & 7.41 & 22.53 & 12.21 & 26.57 & 0.246 \\
\hline Diarrhea & 18.52 & 30.58 & 16.90 & 25.11 & 0.730 \\
\hline Financial problems & 22.54 & 32.745 & 27.70 & 36.07 & 0.373 \\
\hline General health status & 73.96 & 22.68 & 78.05 & 21.39 & 0.269 \\
\hline
\end{tabular}


Table 4 presents the gender comparison in relation to EORTC-QLQ-CR29 scales of body image and symptoms in colorectal cancer patients. Body image, abdominal pain and dry mouth re- present lower quality of life among women. Men have lower quality of life due to the symptoms: fecal incontinence, sexual impotence and sexual arousal.

Table 4. Gender comparison in relation to EORTC-QLQ-CR29 scales of body image and symptoms

\begin{tabular}{lccccc}
\hline \multicolumn{1}{c}{ EORTC-QLQ-CR29 } & Mean & $\begin{array}{c}\text { Male } \\
\text { Standard } \\
\text { deviation }\end{array}$ & Mean & $\begin{array}{c}\text { Standard } \\
\text { deviation }\end{array}$ & p value \\
Body image & 85.96 & 17.88 & 76.85 & 28.45 & 0.023 \\
Scale of Symptoms & & & & & \\
$\quad$ Anxiety & 59.26 & 35.91 & 61.50 & 35.47 & 0.708 \\
Weight & 75.00 & 32.50 & 70.42 & 32.14 & 0.399 \\
Urinary Frequency & 40.51 & 27.94 & 48.84 & 26.73 & 0.070 \\
Blood and mucus in stool & 3.47 & 10.44 & 2.08 & 6.21 & 0.334 \\
Frequency of evacuation & 18.29 & 23.76 & 18.52 & 25.41 & 0.955 \\
Urinary incontinence & 3.70 & 14.32 & 4.23 & 12.51 & 0.817 \\
Dysuria & 5.09 & 14.43 & 3.29 & 11.48 & 0.410 \\
Abdominal pain & 8.80 & 17.68 & 16.90 & 23.14 & 0.020 \\
Pain in the gluteal region & 3.70 & 13.18 & 4.23 & 14.83 & 0.824 \\
Swelling & 19.44 & 25.48 & 21.13 & 29.40 & 0.715 \\
Dry mouth & 20.83 & 29.83 & 38.50 & 33.16 & 0.001 \\
Hair loss & 3.24 & 14.97 & 7.51 & 16.13 & 0.103 \\
Palate & 27.78 & 36.25 & 34.27 & 39.02 & 0.304 \\
Flatulence & 13.43 & 23.51 & 19.25 & 30.16 & 0.201 \\
Fecal incontinence & 11.11 & 20.17 & 1.41 & 6.75 & $<0.001$ \\
Injured skin & 9.26 & 21.09 & 11.27 & 24.52 & 0.600 \\
Embarrassment & 11.11 & 22.37 & 18.78 & 32.72 & 0.104 \\
Problems with stoma & 11.11 & 24.46 & 11.11 & 28.00 & 1.000 \\
Sexual impotence & 1.42 & 0.78 & 1.15 & 0.62 & 0.027 \\
Sexual arousal & 2.18 & 0.96 & 1.49 & 0.85 & $<0.001$ \\
Dyspareunia & 11.11 & 19.24 & 6.47 & 20.3 & 0.699 \\
\hline
\end{tabular}

\section{Discussion}

In both groups there was prevalence of married patients, with elementary education, social class $\mathrm{C}$ and with religious practice. However, men remained active in the labor market, but with sick leave. Women were mostly retired. Still, there was prevalence in both groups of patients with colon tumor, in stage III, undergoing adjuvant treatment and surgery, having a family history of cancer and absence of stoma. A study conducted with 144 Brazilian patients (72 men and 72 women) with colorectal cancer also found a predominance of $66.7 \%$ of patients from social class C $(66.7 \%)$, with complete elementary education $(67.8 \%)$ and living with a partner (69.4\%). ${ }^{(15)}$ In the analysis of clinical characteristics, there was prevalence of colon cancer (85\%), in stages III and IV (47.3\%), 
being submitted to surgery (95.8\%) and adjuvant chemotherapy $(65 \%)$, with a family history of cancer in $60.4 \%$ of the sample. ${ }^{15)}$ In this sense, the sociodemographic profile of patients with colorectal cancer is composed of patients with low educational and income level, who live with a partner or are married. The low level of education can contribute to delay in the recognition of symptoms and search for care in health services. In addition, financial limitations hamper access to private health services, thus requiring the search for public network services, in which a long time is generally observed between the consultation, the diagnosis and the actual treatment of tumors. (16-18) This delay in access and care allows the disease to progress, leading to late diagnosis (stages III and IV), which will require surgery in addition to chemotherapy, with a higher risk of associated mortality. ${ }^{(16-18)}$

The results of this research reveal that, in both genders, cognitive function was the most affected by colorectal cancer, thus contributing to a decrease in general quality of life. However, the impact was greater among men when compared to women. In a study that analyzed 101 patients with colorectal cancer, cognitive function had a similar score (mean $=76.25),{ }^{(19)}$ however, women had lower quality of life related to this factor. On the other hand, a study of 317 patients with gastrointestinal cancer, of whom 145 had colorectal cancer, showed that men with colorectal cancer presented lower quality of life in the domains of physical performance, emotional and cognitive function. ${ }^{(10)}$ Several studies have showed the impact of chemotherapy drugs on the cognitive function of patients. This impact varies according to the chemotherapeutic drugs that constitute the treatment protocol. Thus, a study of 30 patients with gastrointestinal, breast and prostate cancer observed greater side effects in the 5-Fluorouracil $(5-F U)+$ Cyclophosphamide + Doxorubicin protocol. Among the effects mentioned, in addition to changes in the cognitive function, the most outstanding are pain, lack of appetite and constipation. ${ }^{(20)}$ This fact was verified in a study conducted in 317 patients with gastrointestinal cancer - 145 with diagnosis of colorectal cancer - in which the women reported feeling more fatigue, nausea/vo- miting, pain and lack of appetite. ${ }^{(10)}$

It was evidenced that body image, abdominal pain and dry mouth represent lower quality of life to women. Men have lower quality of life due to the symptoms: fecal incontinence, sexual impotence and sexual arousal. A longitudinal research with one year of follow-up after surgery conducted with 75 Japanese (42 male and 33 female) patients with rectal cancer found that women had their overall health and quality of life affected by fatigue, weight loss, problems with defecation and future prospects. On the other hand, among men, fatigue, weight loss, future prospects and role performance was affected by defecation problems and financial difficulties. ${ }^{(21)}$ It is observed that cancer and the effects produced by its treatment lead to important changes in the life of patients, including difficulties of defecation/incontinence and weight loss - which impacts on the perception of the body image - elements that are corroborated by other studies. In addition, pain and fatigue deriving from treatment may explain the poor quality of life presented by men in relation to sexual activity and arousal. In this sense, it is evident how colorectal cancer affects the social life of patients, which results not only from the direct effects of the treatment but also from the outcomes of the disease in the professional field, since there is often a decrease in productivity at work and retirement or sick leave, which leads to social isolation and depression. This is confirmed by research with 100 colon cancer patients in which men pointed out work activities and women social relationships as the elements that most negatively affected quality of life. (22) In addition, although cognitive function had had a greater impact on quality and life in this study, it is necessary to consider the psychological aspect and its effect on the quality of life of men and women. This was verified in a study of 114 patients with different types of tumor in which depression was the strongest predictor of decline in quality of life in both male and female patients. ${ }^{(23)}$

It is concluded that cognitive function leads to lower general quality of life in men when compared to women. Body image, abdominal pain and dry mouth represent lower quality of life for 
women. Men have lower quality of life due to the symptoms: fecal incontinence, sexual impotence and sexual arousal. Thus, it is confirmed that chemotherapy has a negative impact on men and women, but the symptoms of the disease and the treatment that reduce the quality of life differ between the genders. These results allow increasing knowledge about the quality of life from a gender perspective in a Brazilian population. In this sense, the nurse must be aware of the effects of chemotherapy on patients' quality of life, considering the gender differences in the perception of this phenomenon. Thus, in the care context, when evaluating the patient systematically and considering the gender differences in this process, nurses will be able to focus on the elements that contribute to lower quality of life in each group and, thus, to plan and implement individualized and humanized preventive measures and treatment for patients with colorectal cancer undergoing chemotherapy.

As a limitation of this study, we highlight the convenience sampling that does not allow the selection of subjects with a combination of sociodemographic and clinical characteristics in order to make the comparison of the quality of life even more reliable. In this sense, further studies with randomized and numerically larger samplings should be conducted so that the differences in the quality of life between men and women cannot be attributed to other characteristics than those present in the evaluation instrument.

\section{References}

1. INCA. Estimativa 2016 Incidência de Câncer no Brasil. 2016 [cited 2016 Aug 10]. Available from: http://www.inca.gov.br/estimativa/2016/

2. Pollock R, Doroshow J, Khayat D, Nakao A, O'Sullivan B. Manual de Oncologia Clínica da UICC. União Internacional Contra o Câncer. 8th Ed. São Paulo: Fundação Oncocentro de São Paulo; 2006.

3. Saragiotto D, Riechelmann R, Ribeiro Junior $U$, Hoff P. Tumores de cólon. Tratado de oncologia. São Paulo: Atheneu; 2013.

4. Holland JC, Andersen B, Breitbart WS, Buchmann LO, Compas B, Deshields TL, et al. Distress management: NCCN Guidelines; 2011.
5. WHO. WHOQOL-HIV Instrument. Mental Health: evidence and research department of mental health and substance dependence. WHO: Geneva; 2012.

6. EORTC. Quality of Life. 2016 [cited 2016 Aug 10]; Available from: http://www.eortc.org/qualityof-life/.

7. Lewis C, Xun P, He K. Effects of adjuvant chemotherapy on recurrence, survival, and quality of life in stage II colon cancer patients: a 24-month followup. Support Care Cancer. 2016; 24(4):1463-71.

8. Buetto LS, Zago MM. Meanings of quality of life held by patients with colorectal cancer in the context of chemotherapy. Rev. Latino-Am Enferm. 2015; 23(3):427-34.

9. Moreira-Almeida A, Pinsky I, Zaleski M, Laranjeira R. Envolvimento religioso e fatores sociodemograficos: resultados de um levantamento nacional no Brasil. Rev. Psiq. Clin. 2010; 37(1):12-5.

10. Sanchez R, Alexander-Sierra F, Oliveiros R. Relationship between quality of life and clinical status in patients with gastrointestinal cancer. Rev. Esp. Enferm. Dig. 2012; 104(11):584-91.

11. Aaroson NK, Ahmedzai S, Bergman B, Bullinger M, Cull A, Duez N, et al. The European Organization for research and treatment of Cancer QLCC30: a quality-of-life instrument for use in international clinical trials in oncology. J. Natl. Cancer Inst. 1993; 855:365-76

12. Franceschini J, Jardim JR, Fernandes ALG, Jamnik S, Santoro IL. Reprodutibilidade da versão em português do Brasil do European Organization for Research and Treatment of Cancer Core Quality of Life Questionnaire em conjunto com seu módulo específico para câncer de pulmão. J. Bras. Pneumol. 2010; 36(5):595-602.

13. Fayers P, Aaronson N, Bjordal K, Groenvold M, Curran D, Bottomley A. The QLQ-C30 Scoring Manual. Brussels: European Organization for Research and Treatment of Cancer; 2001.

14. EORTC, inventor; EORTC Quality of Life Group, assignee. EORTC QLQ-CR29 Portuguese (Brazil); 2010.

15. Costa AL, Heitkemper MM, Alencar GP, Damiani LP, Silva RM, Jarrett ME. Social Support Is a Predictor of Lower Stress and Higher Quality of Life and Resilience in Brazilian Patients With Colorectal Cancer. Cancer Nurs. 2016 May 11. [Epub ahead of print].

16. Lima-Costa MF, De Oliveira C, Macinko J, Marmot $M$. Socioeconomic inequalities in health in older adults in Brazil and England. Am. J. Public Health. 2012; 102(8):1535-41. 
17. Maringe C, Walters S, Rachet B, Butler J, Fields $\mathrm{T}$, Finan $\mathrm{P}$, et al. Stage at diagnosis and colorectal cancer survival in six high-income countries: a population-based study of patients diagnosed during 2000-2007. Acta Oncol. 2013; 52(5):919-32.

18. Ahmed AA. Clinicopathological profile of female Sudanese patients with locally advanced breast cancer. Breast Dis. 2014; 34(3):131-4.

19. Teker F, Demirag G, Erdem D, Kemal Y, Yucel I. Quality of life in colorectal cancer patients during chemotherapy in the era of monoclonal antibody therapies. J. BUON. 2015; 20(2):443-51.

20. Sawada N, Nicolussi A, Okino L, Cardozo F, Zago M. Avaliação da qualidade de vida de pacientes com câncer submetidos à quimioterapia. Rev. Esc. Enferm. USP. 2009; 43(3):581-7.
21. Kinoshita Y, Chishaki A, Kawamoto R, Manabe T, Ueki T, Hirata K, et al. A longitudinal study of gender differences in quality of life among Japanese patients with lower rectal cancer treated with sphincter-saving surgery: a 1-year follow-up. World J. Surg. Oncol. 2015; 13:91.

22. Domati F, Luppi G, Reggiani-Bonetti L, Zironi S, Depenni R, Fontana A, et al. The perception of health-related quality of life in colon cancer patients during chemotherapy: differences between men and women. Int. Emerg. Med. 2015; 10(4):423-9.

23. Pud D. Gender differences in predicting quality of life in cancer patients with pain. Eur. J. Oncol. Nurs. 2011; 15(5):486-91. 